\title{
Enhancement of Students' Practical Ability in Plane Design Teaching in Colleges and Universities

\author{
Bing Chen
}

Wuhan Vocational College of Software and Engineering, Wuhan Hubei, 432025, China

Key words: Plane design course in colleges and universities, Teaching, Tractical ability, Enhancement.

\begin{abstract}
With the development of society and economy, people's ideological level and art appreciation ability have been further raised. As an art of practice, the specialty of plane design also gradually finds favor in the eyes of colleges and universities, and finally has been taken as a specialized course in colleges and universities. Presently, however, the enhancement of students' practical ability is a prominent problem in plane design teaching of colleges and universities in China.
\end{abstract}

\section{Introduction}

Plane design is a specialty that requires practitioners to have a strong practical ability, and be able to fully transform what they learned into practice. With respect to this aspect, I have made discussions on how to enhance students' practical ability in plane design teaching in colleges and universities, hoping to help plane design majors to enhance their practical ability.

\section{Significance of Practical Ability Enhancement in Plane Design Teaching in Colleges and Universities}

\section{It is good for meeting social demands fast.}

The ultimate of university education is to enable students to have social practice ability, to make contributions via social practice. With the constant development of the society and economy, the talent demand of the society both in quantity and quality is rising year by year, and as the mainstay of delivering talents to the society, university education shoulders heavy responsibilities. Therefore, in concrete university education practice, if emphasis can be laid on training of students' practical ability to teach them solid specialized knowledge and develop strong social adaptation ability, a large number of excellent talents can be provided to address the requirements of social development.

\section{It is good for training students' social competition ability.}

The market brings about infinite possibilities and chances to the development of plane design majors, as well as huge stress and competition. To stand out in fierce competition, students must have solid theoretical knowledge and strong social adaptation ability. Therefore, plane design majors should lay a solid foundation for future social practice in school, regard every course as important, and take every practice seriously. Meanwhile, a good attitude towards learning can win a favorable impression for them during job interview.

\section{It is good for promoting students to realize their value of life.}

If students can acquire solid specialized knowledge and strong adaptation ability in school, they also will develop positive and optimistic attitude towards life, which is of great significance to their own development and realization of value of life. This is because the society is continuously developing and changing quickly, so that students cannot adapt themselves to the society if they cease to advance. 
Therefore, they must develop and temper their social adaptation ability in school, and try their best to learn the essence, so that they can draw inferences about other cases from one instance and cope with shifting events by sticking to a fundamental principle. In the stage of constantly adapting to the society, not only students can create value for the development and prosperity of the society, but also the society will reward them for their efforts and fully affirm and give honors and awards to them, so that plane design majors can create chances for realizing their own value while creating social wealth. Many things can be achieved at one stroke [1].

\section{The practical ability of plane design majors in colleges and universities is insufficient.}

China's higher education has been being affected by the thinking model of "regarding theoretical knowledge as important while ignoring the training of practical ability". Although this thinking model has some effect on college students in theoretical knowledge learning, the teaching objectives of colleges and universities are distinctively different from that of primary school and middle school, especially for the specialty of plane design which requires students to have strong practical ability.

Colleges and universities all fail to be based on the market demand and the characteristics of the specialties, let alone having a correct understanding of training of students' practical ability and giving correct guidance; students at school stand slim chance of social practice, but the major stage where students can improve their practical ability is exactly the society. Besides, the teachers' practical ability is insufficient too. In real teaching, even though they have a clear understanding about how to improve students' practical ability, they are unable to do what they hope to do, because they also have little chance of social practice. Most of them directly turned from a school to another school (graduated from the former and took a post in the latter), and they can hardly have social practice.

Colleges and universities serve as the talent pool of the society. The social development and market prosperity need an ocean of talents with both solid theoretical knowledge and strong social practical ability. Due to an irrational education and teaching mode, the students of most colleges and universities lack the practical ability. And the society lacks related talents. As far as students are concerned, most plane design majors cannot get trust of employers because their practical ability is insufficient. Thus, an embarrassing situation where graduates hardly can find an ideal job, and employers lack talents occurs [2].

\section{Approaches of Enhancing Students' Practical Ability in Plane Design Teaching in Colleges and Universities}

\section{Colleges and universities should change the teaching concept, and make certain teaching objectives.}

In the traditional education and teaching mode of plane design course, emphasis is laid on teachers' attainment and level, but enough attention is not paid to the importance of students, the major subject of study. Thus, students' autonomy in plane design learning has been weakened, and they don't have enough enthusiasm and innovation ability. Hence, various problems occur in the education and teaching of plane design, which are urgent to be solved.

Colleges and universities should designedly and purposefully carry out plane design teaching.

College students are in the turning period of their life, whose presentation skills should be greatly enhanced in school. It is hard to achieve the expected teaching result if the course teaching standards are rigidly followed. Therefore, teachers, at the time of following the course standards, should pay abundant attention to the characteristics of this teaching stage, and emphasize students' learning needs. If students' learning needs are ignored, their presentation skill cannot be remarkably enhanced. Hence, in teaching activities aiming to enhance students' presentation skill, teachers should have a full understanding of the teaching contents, make considerations from multiple perspectives and at multiple layers, and make a teaching plan on this basis; learn about students' hobbies, and design 
teaching activities favored by students on this basis, which cannot only arouse students' learning interest, but also bring about unexpected teaching result to teachers. That students devote themselves to teaching activities means a half success of course teaching has been achieved.

Colleges and universities should make full of multimedia teaching.

In the process of cultivating students' presentation skill in plane design teaching in colleges and universities, efforts must be made to arouse students' enthusiasm; auxiliary teaching equipment also should be made full use of to enhance students' presentation skill in plane design teaching in colleges and universities. With the growing popularity of the internet technology, it is widely applied in various fields in the society, having promoting the integrated development and progress of social undertakings. The educational cause is crucial to a country, so no perfunctoriness is allowed. We will selectively try every means that can boost the development of the educational cause and improve teaching quality. Presently, multimedia teaching software has been introduced in the teaching of plane design in colleges and universities. Making full use of multimedia teaching software is the key to the success of multimedia teaching. Considering the characteristics of college students, the teaching software should contain rich contents to stimulate students' perception, which can lay a foundation for enhancing students' presentation skill. Teachers can take advantage of teaching software to stimulate students' feelings of beauty, so as to enrich students' emotional world, and help them develop divergent thinking.

Colleges and universities should drastically change the practice method.

The core of the teaching of presentation skill is to encourage students to voice their ideas bravely. Therefore, regular practice is effective for enhancing students' presentation skill. In teaching process, group discussion is a common method of enabling students to communicate, learn and express, which can promote the enhancement of students' presentation skill to a certain extent, but is not the best method. Therefore, to fundamentally enhance students' presentation skill, teachers should make greater efforts to designing more scenarios to let students learn and grasp related presentation skills and methods via situational simulation.

\section{Colleges and universities should update the teaching methods, and create good learning atmosphere.}

Colleges and universities should strengthen practical teaching, to train students' application ability. Plane design is a course requiring a strong practical ability. Besides some basic knowledge and skills, students must apply knowledge in living practice to truly master plane design, which is helpful for forming good views and values. To achieve this aim, teachers should give positive and correct guidance, so as to promote all-round development of students. It is not difficult to find that the development of comprehensive abilities of plane design is closely related to our life. Students can learn related plane design knowledge and abilities from the real life. Emotional education via practice is effective for enriching students' emotions, to greatly enhance students' abilities of knowledge understanding and application. The enhancement of knowledge application means students have learned to apply their knowledge, which is exactly the ultimate goal of education.

Colleges and universities should create a harmonious classroom situation, to stimulate students' learning interest.

A good classroom learning atmosphere is good for achieving the effect of yielding twice the result with half the effort in teaching. Meanwhile, it also can enhance affective interaction between teachers and students. Therefore, in the teaching process of plane design in colleges and universities, teachers should make greater efforts to creating a good classroom atmosphere. The introduction of multimedia teaching and teaching software has largely facilitated teachers in creating a good classroom atmosphere. With the help of multimedia software, teachers can vividly and visually introduce knowledge that students should learn and grasp, to help students deeply understand texts, make certain the emotional route of articles, and grasp the main idea of articles. There is no lack of emotional articles in teaching materials of colleges and universities, of which some kind of emotions can be felt only. Thus, teachers should help students to truly feel the emotions of characters in articles 
with the help of some teaching means. This teaching method can largely arouse students' interest, and help students to devote themselves to learning.

\section{Teachers should take positive action to arouse students' initiative in learning.}

Teachers should learn to enlighten and guide students.

In the process of teaching and learning, teachers always act as an important role of guide. Therefore, that teachers correctively and effectively guide students is of great importance, which is exactly the interpretation of "methodical and patient guidance". On in this way, students' abilities can be enhanced. Thus, how to enlighten and guide students has become a topic worthy of attention in the teaching process. The ultimate goal of teaching is to enhance students' abilities. As to the transformation of the knowledge of textbook into students' abilities, teachers should make great efforts from many aspects, such as the characteristics of teaching material, teaching method, and the aid of teaching means. The process of teachers enlightening and guiding is actually a process in which students temper their thinking and learning abilities. In this process, students can acquire knowledge and enhance their abilities via thinking, analyzing and researching, and then become more confident, and interested in learning.

Teachers should be good at creating situations.

In recent years, situational teaching has attracted a lot of attention from teachers. Especially, the advantages of this teaching mode are more prominent in plane design teaching. In real teaching process, the common method of situation creation is multidimensional thinking method. This method refers to that teachers are required to design a question that can be considered from multiple angles and at multiple layers, and students are required to positively think to answer questions and express their ideas, such as historical background, local conditions and customs and anecdotes involved in texts. Such questions cannot be solved just by answering "right or wrong”. Instead, students should truly understand the meanings, and grasp the knowledge. This method is helpful to not only deepen students' understanding of literature works, but also enhance students' ability of appreciating literature works.

Teachers should guide students to recognize and analyze problems.

Good teachers would not follow the "Duck-stuffing” type of teaching, but teach students to recognize and solve problems with a scientific method. "Give a man a fish and you feed him for a day" has verified this truth. The teaching materials of plane design of colleges and universities offer a lot of excellent works that combine imaginal thinking with logical thinking, and teachers should encourage students to express their ideas, which is good for the development and progress of students' ability of thinking. If any student fails to raise a good question, teachers should not criticize him in the public, because the student's learning initiative will be greatly dampened. Instead, teachers should encourage him and correct him.

Teachers should support students to make communication and exchange, and express their ideas. In real teaching process, various problems will occur. To consolidate students' knowledge and help students to enjoy learning, group discussion is a good method for teaching if students need to raise questions and make discussions. In the discussion process, students should be encouraged to express their ideas and communicate with other group members, which is good for enhancing students' presentation skill and initiative [3].

\section{Conclusion}

To sum up, the teaching phase in colleges and universities, as the most important phase for college students to learn plane design, plays an important role in the learning of plane design, which must be sufficiently emphasized. The teaching quality in colleges and universities determines the development of college students in future. Under the context of the new curriculum reform of elementary education, the education and teaching of plane design falls into an unexpected dilemma. But as long as teachers and students learn and make progress together, the education and teaching of plane design is promising. 


\section{References}

[1] Gao Yuan. Enhancement of Students' Practical Ability In Plane Design Teaching in Colleges and Universities. Large Stage,2015,07:162-163.

[2] Ren Ran. A Brief Analysis of Enhancement of Students' Practical Ability In Plane Design Teaching in Colleges and Universities. Art Education Research, 2014, 01:158-159.

[3] Jiang Liesi. Humbly on How to Raise the Level of Practical Teaching of Plane Design Course in Colleges and Universities. Art And Design (Theory), 2014, 08:158-159. 